\title{
Histone deacetylase 8 is deregulated in urothelial cancer but not a target for efficient treatment
}

\author{
Maria Lehmann', Michèle J Hoffmann' ${ }^{1}$ Annemarie Koch', Scott M Ulrich², Wolfgang A Schulz \\ and Günter Niegisch ${ }^{1 *}$
}

\begin{abstract}
Background: Previous studies have shown that class-I histone deacetylase (HDAC) 8 mRNA is upregulated in urothelial cancer tissues and urothelial cancer cell lines compared to benign controls. Using urothelial cancer cell lines we evaluated whether specific targeting of HDAC8 might be a therapeutic option in bladder cancer treatment.
\end{abstract}

Methods: We conducted siRNA-mediated knockdown and specific pharmacological inhibition of HDAC8 with the three different inhibitors compound 2, compound 5, and compound 6 in several urothelial carcinoma cell lines with distinct HDAC8 expression profiles. Levels of HDAC and marker proteins were determined by western blot analysis and mRNA levels were measured by quantitative real-time PCR. Cellular effects of HDAC8 suppression were analyzed by ATP assay, flow cytometry, colony forming assay and migration assay.

Results: Efficient siRNA-mediated knockdown of HDAC8 reduced proliferation up to 45\%. The HDAC8 specific inhibitors compound 5 and compound 6 significantly reduced viability of all urothelial cancer cell lines $\left(I_{50} 9-21 \mu \mathrm{M}\right)$. Flow cytometry revealed only a slight increase in the sub-G1 fraction indicating a limited induction of apoptosis. Expression of thymidylate synthase was partly reduced; PARP-cleavage was not detected. The influence of the pharmacological inhibition on clonogenic growth and migration show a cell line- and inhibitor-dependent reduction with the strongest effects after treatment with compound 5 and compound 6 .

Conclusions: Deregulation of HDAC8 is frequent in urothelial cancer, but neither specific pharmacological inhibition nor siRNA-mediated knockdown of HDAC8 impaired viability of urothelial cancer cell lines in a therapeutic useful manner. Accordingly, HDAC8 on its own is not a promising drug target in bladder cancer.

Keywords: Histone deacetylase 8, Histone deacetylase inhibitor, Urothelial bladder cancer, Cell cycle arrest

\section{Background}

Bladder cancer is the seventh most common cancer type worldwide with about 300,000 newly diagnosed cases per year [1]. One-third of the patients are diagnosed with a muscle invasive carcinoma and up to $50 \%$ of patients already present with or developed metastases within the first two years. While patients with a nonmuscle invasive papillary urothelial carcinoma expect a rather good prognosis, long term survival of patients suffering from metastatic disease does not exceed 20\% [2]. Although significant responses rates are observed

\footnotetext{
* Correspondence: Guenter.Niegisch@med.uni-duesseldorf.de

'Department of Urology, Heinrich-Heine-University, Medical Faculty,

Moorenstr. 5, Duesseldorf 40225, Germany

Full list of author information is available at the end of the article
}

after treatment with cisplatin based combination chemotherapy, the majority of patients will develop disease recurrence presenting with cisplatin resistance [3-5].

Epigenetic alterations have been proposed as a driving force of malignancy [6-8]. In particular, histone deacetylases (HDACs) are associated with the development and progression of several cancer types $[9,10]$. The human HDAC family is composed of 18 genes and is classified based on the sequence homology to their yeast orthologues Rpd3, HdaI and Sir2 and their domain organization: HDAC1, HDAC2, HDAC3 and HDAC8 (class I); HDAC4, HDAC5, HDAC7 and HDAC9 (class IIa); HDAC6 and HDAC10 (class II b); HDAC11 (class IV) and seven sirtuins (class III) [11-13]. The classical HDACs catalyze the $\mathrm{Zn}^{2+}$ dependent deacetylation of acetyl-lysine residues [11]. Expression profiles of 
class I HDACs are prognostic in various malignancies e.g. gastric, prostate and ovarian cancer [14-16]. In general, HDACs are considered to act as transcriptional corepressors because high HDAC activity is associated with transcriptionally inactive chromatin $[17,18]$. Although many HDACs deacetylate histones the analysis of the human acetylome indicates that the deacetylation of non-histone proteins represents a considerable part of their action $[19,20]$. Substrates include p53 [21], cohesion subunit SMC3 [22] and $\alpha$-tubulin [23]. HDAC inhibitors are useful in the therapy of several hematological malignancies and are currently also investigated in the treatment of solid cancers $[24,25]$.

The expression of HDAC8 has been described in a variety of cancer entities e.g. colon, breast lung, pancreas and ovary cancer [26]. HDAC8 is the most recently identified class I HDAC. It is a protein of 377 amino acids and contains a NLS in the center of the catalytic domain [27-29]. HDAC8 has a conserved motif for phosphorylation by protein kinase A (PKA), which negatively impacts its catalytic activity [30,31]. While class I HDAC family members form nuclear multiprotein complexes that interact with other chromatin modifiers and transcription factors, HDAC8 has not been found to do so [17]. Its intracellular localization seems to depend on the cell type. In gastric adenocarcinoma, esophageal squamous carcinoma, prostate adenocarcinoma and breast carcinoma HDAC8 localization has been described as both nuclear and cytosolic but as exclusively nuclear for non-cancerous gastric, esophageal or prostate epithelium [26]. A predominantly cytosolic distribution of HDAC8 was described for prostate cancer cells [32] and for differentiating smooth muscle cells [33].

In the highly malignant childhood cancer neuroblastoma high HDAC8 expression significantly correlates with poor prognostic markers and poor overall and event-free survival. In cultured neuroblastoma cells knockdown and pharmacological inhibition of HDAC8 resulted in inhibition of proliferation, reduced clonogenic growth, cell cycle arrest and differentiation [34]. Furthermore, HDAC8 specific inhibition selectively induces apoptosis in T-cell derived lymphoma and leukemic cells [35]. In hepatocellular carcinoma overexpression of HDAC8 promotes proliferation and inhibits apoptosis. HDAC8 knockdown inhibits proliferation and enhances apoptosis in hepatocellular carcinoma cells via up-regulation of p53 [36]. In human breast cancer cell lines overexpression of HDAC1, HDAC6 or HDAC8 contributes to increased invasion and metalloproteinase-9 (MMP-9) expression [37]. Furthermore, HDAC8 promotes lung, colon and cervical cancer cell proliferation [31] and may regulate telomerase activity [38].

A recently published analysis of HDAC expression patterns in urothelial carcinoma cell lines and tissues showed a deregulation of several HDACs in urothelial cancer. These findings include up-regulation of HDAC2 and HDAC8 and down-regulation of HDAC4, HDAC5, and HDAC7 [39]. Given the promising results in neuroblastoma [35], we sought to determine whether the selective targeting of HDAC8 might serve as an appropriate therapy for urothelial carcinoma.

\section{Methods \\ Cell culture and treatment}

The urothelial cancer cell lines (UCCs) VM-CUB1, RT-112, SW-1710, 639-V and UM-UC-3 were cultured in DMEM GlutaMAX-I (Gibco, Life Technologies, Darmstadt, Germany) supplemented with $10 \%$ fetal calf serum (GE Healthcare, Piscataway, $\mathrm{NJ}$ ) at $37^{\circ} \mathrm{C}$ and $5 \% \mathrm{CO}_{2}$. Cell lines used were provided by Dr. M. A. Knowles (Leeds, UK), Dr. J. Fogh (New York, USA), Dr. Barton Grossmann (Houston, USA) and by the DSMZ (Braunschweig, Germany). Normal urothelial control (NUC) cells were isolated from ureters after nephrectomy and were cultured in keratinocyte serum-free medium (Invitrogen, Life Technologies, Darmstadt, Germany) supplemented with $0.25 \mathrm{ng} / \mathrm{ml}$ epidermal growth factor and $12.5 \mu \mathrm{g} / \mathrm{ml}$ bovine pituitary extract [40].

Experiments with inhibitors were performed $24 \mathrm{~h}$ after seeding of the cells with a single dose of the selective HDAC8-inhibitors compound 2 (c2; 1-napthohydroxamic acid, (abcr GmbH \& Co, Karlsruhe, Germany), compound 5 (c5, $\delta$-naphtyl-trans 2-butenoil hydroxamic acid) and compound 6 (c6, 4-naphtyl-benzoil hydroxamic acid) or the pan HDAC-inhibitor SAHA (suberoylanilide hydroxamic acid; \#1009929, Cayman Chemicals, Ann Arbor, MI). C5 and c6 are investigational compounds (described in [41]) and are available on request. Inhibitors were dissolved in DMSO as a stock of $10 \mathrm{mM}$. Control cells were treated with DMSO only.

\section{SiRNA mediated knockdown of HDAC8}

UCCs were seeded in 6-well plates and grown for $24 \mathrm{~h}$ before transfection. Cells were transfected with $10 \mathrm{nM}$ HDAC8 Silencer ${ }^{\oplus}$ Select validated siRNA (\#4390824, s31698, Ambion, Life Technologies, Darmstadt, Germany) or a Silencer ${ }^{\bullet}$ Select Negative Control \#2 validated siRNA (\#4390846, Ambion, Life Technologies, Darmstadt, Germany) using Lipofectamine RNAi MAX (Invitrogen, Life Technologies, Darmstadt, Germany), according to the manufacturer's protocol. After transfection cells were incubated for $72 \mathrm{~h}$ before use for further experiments.

\section{Determination of mean inhibitory concentrations $\left(\mathrm{IC}_{50}\right)$ and viability}

The mean inhibitory concentrations $\left(\mathrm{IC}_{50}\right)$ and cell viability were measured trough total cellular ATP as an indicator for viable cells using the CellTiter-Glo ${ }^{\oplus}$ Luminescent Cell Viability Assay (Promega, Mannheim, Germany). UCCs were seeded into 96-well plates and grown for $24 \mathrm{~h}$ before 
inhibitor treatment with the indicated drug concentration or DMSO and further grown for $72 \mathrm{~h}$. In another experiment, cells were plated in 6-well plates and grown for $24 \mathrm{~h}$ before siRNA-mediated knockdown of HDAC8. Viability measurements were performed after $72 \mathrm{~h}$ by transferring the cells into 96-well plates using CellTiter-Glo Reagent according to manufacturer's protocol in a Wallac Victor 1420 Multilabel Counter (PerkinElmer, Rodgau, Germany).

\section{Colony forming assay and Giemsa-staining}

The colony forming assay was carried out $72 \mathrm{~h}$ after siRNA mediated HDAC8 knockdown and HDAC8 inhibitor treatment. Then, cells were plated in 6-well plates at a density of 500 to 1,000 cells per well. After 10 days, cells were washed with PBS (Biochrom, Merck Millipore, Berlin, Germany), shortly fixed in 50\% methanol and incubated for 10 min in $100 \%$ methanol. The colonies were stained with Giemsa (Merck, Darmstadt, Germany). Colony number and size was determined with ImageJ software (http://rsbweb.nih.gov/ij/).

\section{Cell cycle analysis by flow cytometry}

UCCs were transfected with HDAC8 siRNA or an irrelevant control siRNA or, in another experiment, cultured with the determined $\mathrm{IC}_{50}$ concentrations of the HDAC8 selective inhibitors c2, c5 and c6, the pan HDAC-inhibitor SAHA $(2.5 \mu \mathrm{M})$ or DMSO. Cell cycle analysis was performed after $72 \mathrm{~h}$ by staining the attached cells and cells in the supernatant with a PI-buffer containing 50 $\mu \mathrm{g} / \mathrm{ml}$ propidium iodide, $0.1 \%$ sodium citrate and $0.1 \%$ Triton X-100 [42] and flow cytometry using a BD LSR Fortessa cell analyzer system and FACSDiva software 6.2 (Becton Dickinson Biosciences, Heidelberg, Germany).

\section{Migration assay}

Cell migration was determined in wound healing assays by means of Ibidi Culture-Insert (Ibidi, Martinsried, Germany). The cell suspension was placed in both compartments allowing growth in the designated area only. The cells were treated with $\mathrm{IC}_{50}$ concentrations of $\mathrm{c} 2$, c5, c6 or $2.5 \mu \mathrm{M}$ SAHA $48 \mathrm{~h}$ prior to plating. The Culture-Insert was removed $24 \mathrm{~h}$ after cell attachment creating a cell-free gap of approximately $500 \mu \mathrm{m}$ in a confluent cell layer. The extent of wound closure was examined by phase contrast microscopy with the LuciaG software (Laboratory Imaging s.r.o., Prague, Czech Republic) at time points 0 , $3,6,9,12$ and $24 \mathrm{~h}$.

\section{RNA isolation and quantitative real-time PCR}

Total RNA from cell culture was isolated by the Qiagen RNeasy Mini Kit (Qiagen, Hilden, Germany) according to the manufacturer's protocol. Synthesis of cDNA was performed using QuantiTect Reverse Transcription Kit (Qiagen, Hilden, Germany) with an extended incubation time of $30 \mathrm{~min}$ at $42^{\circ} \mathrm{C}$. QRT-PCR was performed using an ABI 7500 Fast PCR instrument (Life Technologies, Darmstadt, Germany) with QuantiTect SYBR Green RT-PCR Kit (Qiagen, Hilden, Germany) according to the manufacture's protocol. To determine the expression levels of HDAC1 (\#QT00015239), HDAC2 (\#QT00001890), HDAC3 (\#QT00093730) and HDAC8 (\#QT00049630) we used QuantiTect Primer assays (Qiagen, Hilden, Germany) at an annealing temperature of $55^{\circ} \mathrm{C}$. The expression of the housekeeping gene TATA-box binding protein (TBP) was determined with self-designed primers (forward: 5'-ACAACAGCCTGCCACCTTA-3'; reverse: 5'-GAATA GGCTGTGGGTCAGT-3'). Technical duplicates had less than $10 \%$ standard deviation.

\section{Western blot analysis}

Western blot analysis of whole-cell extracts were done as described previously [39]. Total protein was extracted by cell lysis in a RIPA-buffer containing $150 \mathrm{mM} \mathrm{NaCl}, 1 \%$ Triton X-100, 0.5\% desoxycholate, 1\% Nonidet P-40, 0.1\% SDS, $1 \mathrm{mM}$ EDTA, $50 \mathrm{mM}$ Tris $(\mathrm{pH} \mathrm{7,6)}$ and a protease inhibitor cocktail (10 $\mu \mathrm{l} / \mathrm{ml}$, \#P-8340, Sigma-Aldrich) for 30 minutes on ice. Protein concentrations were determined by BCA protein assay (Thermo Scientific, Rockford, IL). After separation in SDS-page gels and transfer to PVDF membranes (Merck Millipore, Berlin, Germany) the membranes were blocked with $5 \%$ non-fat milk in TBST (150 mM NaCl, $10 \mathrm{mM}$ Tris, $\mathrm{pH} 7.4$ and 0.1\% Tween-20), washed and then incubated with primary antibodies at room temperature for $1 \mathrm{~h}$ or at $4^{\circ} \mathrm{C}$ over night. Primary antibodies were used against HDAC1 (1:1,000, C-19, sc-6298; Santa Cruz Biotechnology, Heidelberg, Germany), HDAC2 (1:5,000, H-54, sc-7899; Santa Cruz Biotechnology, Heidelberg, Germany), HDAC3 (1:1,000, H-99, sc-11417; Santa Cruz Biotechnology, Heidelberg, Germany), HDAC8 (1:400, A-4008; Epigentek, Brooklyn, NY), p21 (1:400, C-19, sc-397; Santa Cruz Biotechnology, Heidelberg, Germany), thymidylate synthase $(1: 1,000$, TS, TS106, Millipore, Temecula, CA), PARP (poly [ADP-ribose] polymerase 1, 1:500, 46D11; Cell Signaling Technology, Inc., Danvers, MA) and acetylated $\alpha$-tubulin (1:15,000, \#T-7451, Sigma Aldrich, St. Louis, Mo). Anti- $\alpha$-Tubulin B-512 (Sigma Aldrich, St. Louis, MO) was used as loading control in a concentration of 1:50,000. Secondary antibodies were HRP-conjugated goat-anti-mouse antibody (sc-2005; Santa Cruz Biotechnology, Heidelberg, Germany), HRPconjugated goat-anti-rabbit antibody (sc-2004, Santa Cruz Biotechnology, Heidelberg, Germany) and HRP-conjugated rabbit-anti-goat antibody (P0160; DakoCytomation, Stockholm, Sweden) at a concentration of 1:10,000 to $1: 100,000$. Bands were visualized by the ECL select chemo luminescence kit (GE Healthcare, Piscataway, NJ) and the WesternBright Quantum kit (Biozym, Hessisch Oldendorf, Germany). 


\section{Extraction, purification and analysis of histones}

Histones were extracted following a published protocol through sulphuric acid extraction and TCA-precipitation [43]. One $\mu \mathrm{g}$ of each sample was used for western blot analysis with 15\% SDS-PAGE gels and PVDF membranes (Merck Millipore, Berlin, Germany) according to the previously-described protocol. The detection of acetylated and non-acetylated histones was performed with primary antibodies against acetylated histone H3 (1:2,000, \#39139, Active Motif, La Hulpe, Belgium), total histone H3 (1:1,000, \#3638, Cell Signaling Technology, Inc., Danvers, MA), acetylated histone H4 (1:1,000, \#39243, Active Motif, La Hulpe, Belgium) and total histone H4 (1:500, \#39269, Active Motif, La Hulpe, Belgium).

\section{Statistical analysis}

Statistical analyses were performed using SPSS 18 (SPSS, Chicago, USA). Significance was measured by the student's t-test and no-parametric Mann-Whitney $\mathrm{U}$ test. P-values of $<0.05$ were considered as significant whereas $\mathrm{p}<0.01$ and $\mathrm{p}<0.001$ were defined as highly significant. $\mathrm{IC}_{50}$ values and dose-response curves were approximated by non-linear regression analysis using Origin 8.0 (Origin Lab, Northhampton, GB).

\section{Results}

HDAC8 mRNA and protein expression in urothelial cancer cell lines and uroepithelial cells

Urothelial bladder cancer is a heterogeneous disease with diverse clinical, pathological, genetic and epigenetic presentations. As recently published [39], overexpression of HDAC8 was observed in cancer tissues. In urothelial cancer cell lines, a variable expression of HDAC8 was observed both at mRNA and protein level.

To cover this range, we chose a panel of cell lines representing the heterogeneity of the tumor. The mRNA level of HDAC8 was more than twofold upregulated in the UCC UM-UC-3 compared to NUCs. In contrast, UCC RT-112 cells showed a decreased level of HDAC8 mRNA (Figure 1A). The HDAC8 mRNA expression in UCCs was comparable to the measured HDAC8 expression in other tumor entities such as neuroblastoma and mammary carcinoma (data not shown). The HDAC8 protein levels are shown in Figure 1B. The UCC SW-1710 indicated a strong increase of HDAC8 protein compared to NUCs. The cell lines VM-CUB1 and UM-UC-3 showed a moderate increase of HDAC8. In the cell line 639-V, a reduction of HDAC8 protein expression was observed.

Accordingly the urothelial carcinoma cell lines SW-1710 (protein level strongly increased), UM-UC-3, VM-CUB1 (protein level moderately increased), RT-112 (protein level as normal) and 639-V (protein level decreased) were selected for further experiments.

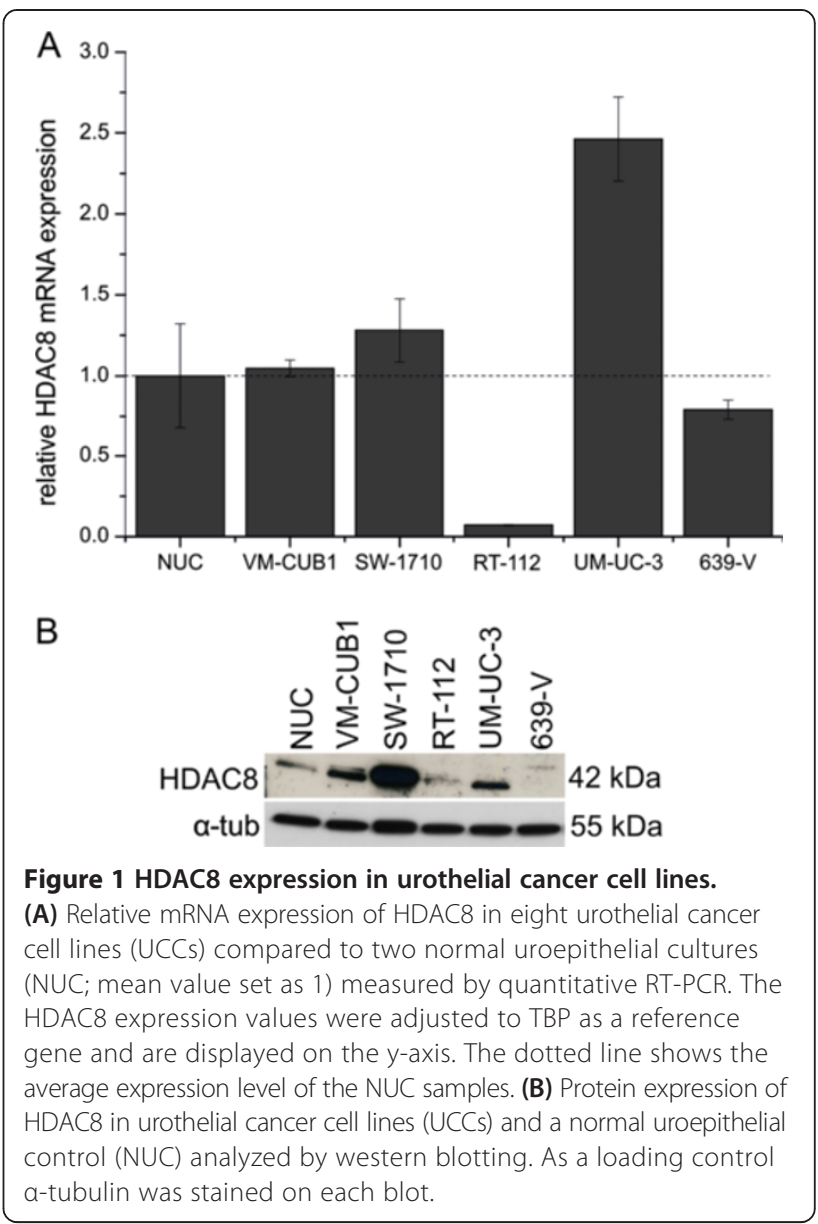

Effects of siRNA-mediated knockdown of HDAC8 on cell proliferation and clonogenic growth of urothelial carcinoma cells

The endogenous HDAC8 expression was reduced by transiently transfecting HDAC8 siRNA and irrelevant siRNA into RT-112, VM-CUB1, SW-1710, 639-V and UM-UC-3 cells. The knockdown efficacy $72 \mathrm{~h}$ after transfection was shown by RT-PCR (Figure 2A) and western blot analysis (Figure 2B). The UCCs RT-112, VM-CUB1, SW-1710 and UM-UC-3 indicated a HDAC8 knockdown of about $90 \%$ to $95 \%$. In $639-\mathrm{V}$ cells, a knockdown of $55 \%$ was achieved.

To investigate the impact of HDAC 8 on cell proliferation of UCCs we performed viability assays after $72 \mathrm{~h}$ of transfection. Targeting HDAC8 with siRNA caused a $20 \%$ to $45 \%$ reduction of cell growth compared to the irrelevant control (Figure 3A). Colony forming assays were performed to evaluate the role of HDAC8 for anchoragedependent clonal growth capability. The siRNA mediated HDAC8 knockdown inhibited clonogenic growth of UCCs (Figure 3B). The transfection of HDAC8 siRNA in VMCUB1 and UM-UC-3 cells caused a moderate reduction of colony numbers compared to transfection of irrelevant siRNA by up to $30 \%$. The relative size of the HDAC 8 


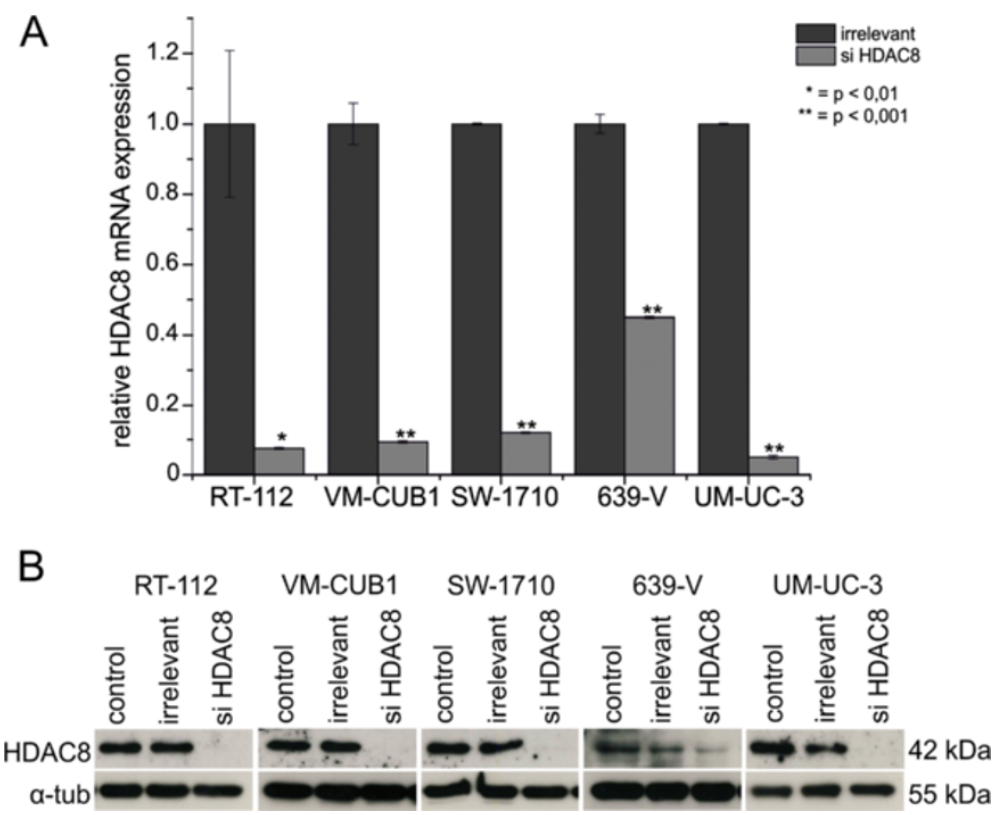

Figure 2 Efficiency of HDAC8 knockdown by a specific siRNA in the urothelial cancer cell lines. (A) Relative HDAC8 expression after siRNA mediated knockdown in urothelial carcinoma cell lines compared to irrelevant control as examined by quantitative RT-PCR analysis (72 h). The HDAC8 expression values were normalized to TBP as a reference gene and are displayed on the $y$-axis. $p<0.01$ and $p<0.001$ were defined as highly significant and marked as * and **. (B) Western blot analysis confirmed the effects of HDAC8-siRNA mediated knockdown at the HDAC8 protein level in comparison to normal and irrelevant siRNA controls (72 h). As a loading control a-tubulin was stained on each blot.

siRNA transfected colonies is reduced in 639-V in comparison to irrelevant siRNA. In VM-CUB1, SW-1710, RT-112 and UM-UC-3 cells the colony size remains constant between irrelevant control and HDAC8 siRNA transfection (data not shown).
To characterize the effect of the HDAC8 knockdown on UCCs, we investigated downstream targets of HDAC8 known from other cancers: the proliferation marker thymidylate synthase (TS), cleavage of PARP and expression of p21. In addition, we examined the acetylation status of

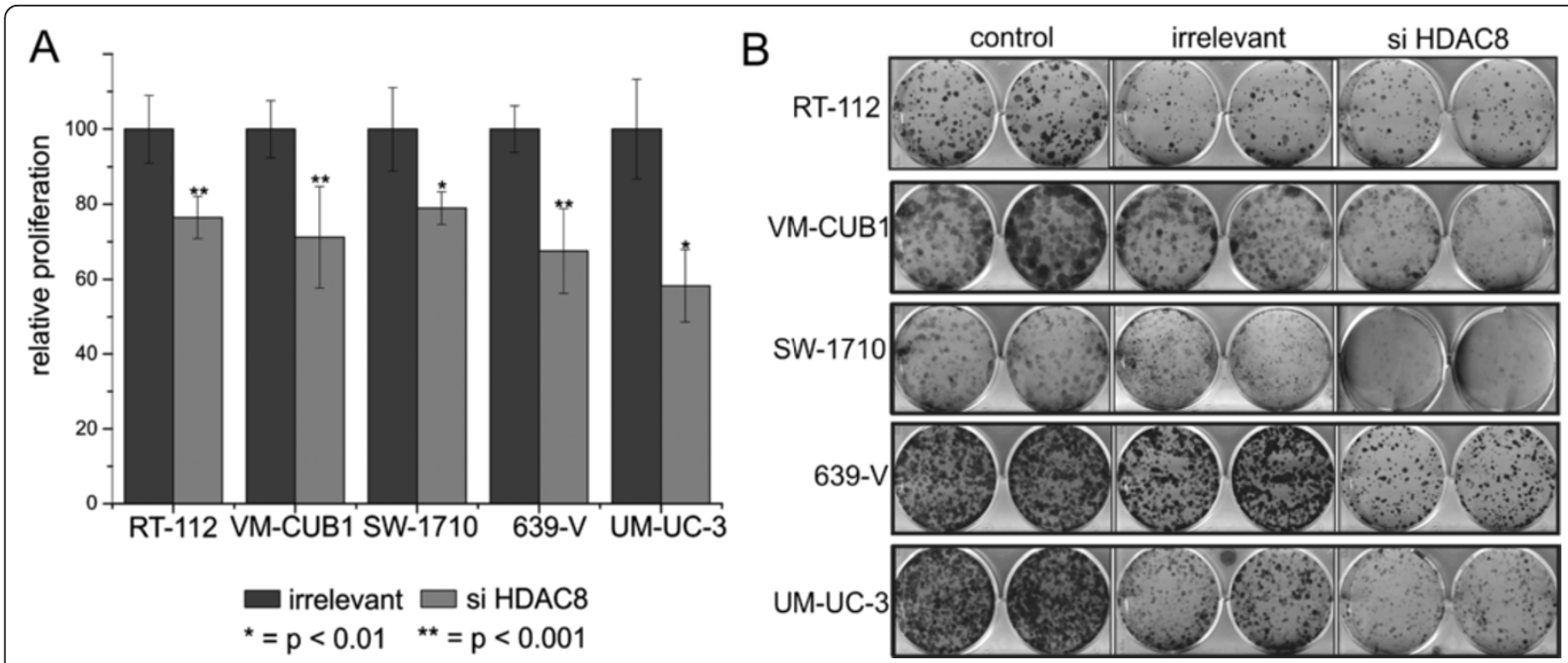

Figure 3 Proliferation and clonogenicity in urothelial cancer cells after siRNA mediated knockdown of HDAC8. (A) Relative cell viability in several urothelial carcinoma cell lines after siRNA mediated knockdown of HDAC8 compared to irrelevant control (72 h). The percentage of viable cells was measured by ATP-assay and is displayed on the $y$-axis. $p<0.01$ and $p<0.001$ were defined as highly significant and marked as * and ${ }^{* *}$. (B) Giemsa-staining of colonies from irrelevant siRNA and HDAC8 siRNA transfected RT-112, VM-CUB1, SW-1710, 639-V and UM-UC-3 cells compared to an untreated control (72 h). 
$\alpha$-tubulin to estimate the specificity of the HDAC8 treatment (Figure 4). The expression of TS $72 \mathrm{~h}$ after HDAC8 knockdown was only slightly reduced in SW-1710, 639-V and UM-UC-3 cells. In RT-112 and VM-CUB1 cells no effects were observed. Effects on cleavage of PARP could only be detected in UM-UC-3 cells after HDAC8 knockdown. There a decrease can be observed. The expression level of p21 indicates a decreased expression in comparison to irrelevant control in the cell lines RT-112, VM-CUB1, 639-V and UM-UC-3 after HDAC8 knockdown. In the cell line SW-1710 no altered p21 expression could be observed. An increase of acetylated $\alpha$-tubulin could be detected in all cell lines after HDAC8 siRNA transfection (Figure 4).

\section{Effects of HDAC8 specific hydroxamic acid inhibitors on urothelial carcinoma cells}

Based on the observation that the HDAC8 knockdown inhibited proliferation of urothelial carcinoma cells we investigated the sensitivity of several UCCs to three different HDAC8 inhibitors [41]. The treatment with the HDAC8 selective small molecule inhibitors c2, c5 and c6 inhibited the cell proliferation of all UCCs in a concentration dependent manner, with stronger effects of the higher affinity compounds c5 and c6 (Table 1). The three dose response curves for the cell line RT-112 in Figure 5A show a low sensitivity for $\mathrm{c} 2$ with a calculated $\mathrm{IC}_{50}$ value greater than $50 \mu \mathrm{M}$ and a higher sensitivity for c5 and c6 with an $\mathrm{IC}_{50}$ value of about $9.7 \mu \mathrm{M}$ and $9.1 \mu \mathrm{M}$.

While c5 and c6 significantly reduced the viability of all UCCs, their effect varied among the cell lines. It is noticeable that cells with an epithelial phenotype e.g. RT112 were more sensitive than cells with a mesenchymal phenotype (SW-1710 and UM-UC-3; Figure 5B).

The influence of the inhibitors on clonogenic growth after a $72 \mathrm{~h}$ treatment at the determined $\mathrm{IC}_{50}$ concentrations is illustrated in Figure 6. Compound 2 inhibited
Table 1 Stated are $I_{50}$ values after $72 \mathrm{~h}$ of HDAC8 inhibitor treatment in eight urothelial cancer cell lines and a representative normal uroepithelial control

\begin{tabular}{|c|c|c|c|c|}
\hline & $\mathrm{IC}_{50}[\mu \mathrm{M}]$ & Compound 2 & Compound 5 & Compound 6 \\
\hline VM-CUB1 & & $\geq 50$ & 18.7 & 16 \\
\hline SW-1710 & & $\geq 50$ & 20.8 & 18.8 \\
\hline RT-112 & & $\geq 50$ & 9.7 & 9.1 \\
\hline $639-V$ & & $\geq 50$ & 12.6 & 18.6 \\
\hline UM-UC-3 & & $\geq 50$ & 18.9 & 18.2 \\
\hline $\begin{array}{l}\text { Normal } \\
\text { Uroepithelial } \\
\text { Control }\end{array}$ & & $\geq 50$ & 24.2 & 10.2 \\
\hline
\end{tabular}

clonogenicity only in VM-CUB1 cells. Treatment with compound 5 resulted in a moderate reduction of colony numbers in RT-112, UM-UC-3 and 639-V cells, whereas in VM-CUB1 cells, clonogenic growth was completely abolished. In contrast, c5 had no effect on SW-1710 cells. Compound 6 was active in all cell lines, being most efficient in VM-CUB1, UM-UC-3 and 639-V cells.

As the effect of pharmacological HDAC8 inhibition was stronger than the effect of HDAC8 knock-down, wound healing assays of UCCs after HDAC8 inhibitor treatment were additionally performed (Figure 7A). A clear difference was observed in VM-CUB1 and UM-UC-3 cells, respectively, comparing DMSO controls to cells treated with c5 and c6, especially after 6 - 12 h (Figure 7B).

The impact of the HDAC8 inhibitor treatment was further analyzed by western blot analysis of different target proteins (Figure 8). The expression of thymidylate synthase (TS) in VM-CUB1, SW-1710 and UM-UC-3 cells was weakly reduced after $72 \mathrm{~h}$ of c5 and c6 treatment. No effects were observed in 639-V and RT-112 cells. Increased cleavage of PARP after c6 treatment could be only detected in the UCC SW-1710. Effects on p21 were divergent. In

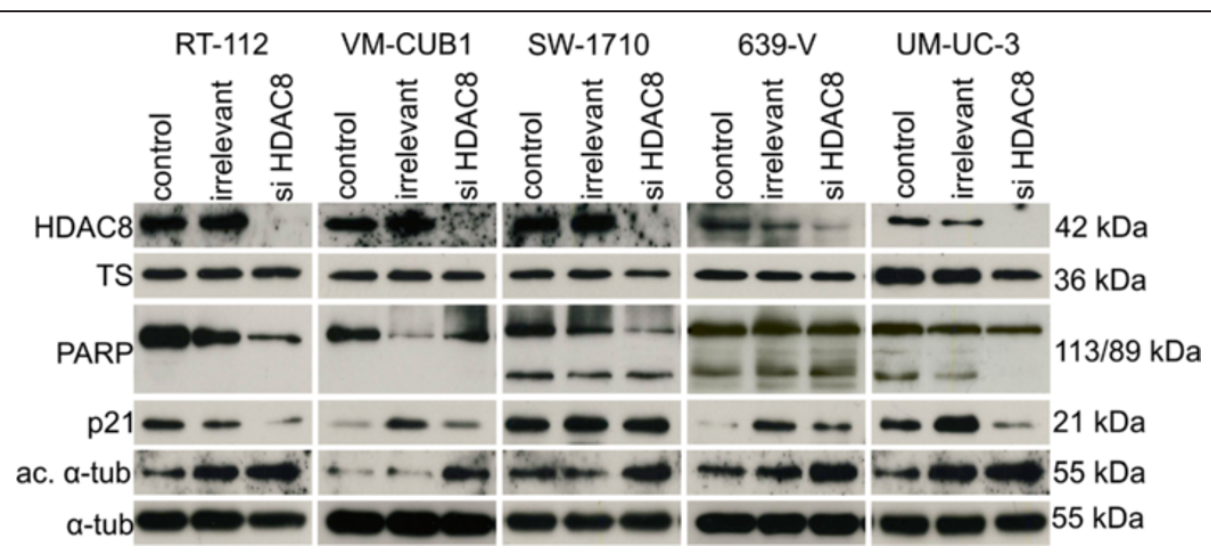

Figure 4 Effects of siRNA mediated HDAC8 knockdown on target proteins. PARP, p21, acetylated a-tubulin and thymidylate synthase (TS) protein expression levels subsequent to HDAC8 knockdown were determined by western blot analysis in comparison to a irrelevant control in the UCCS RT-112, VM-CUB1, SW-1710, 639-V and UM-UC-3 (72 h). As a loading control a-tubulin was stained on each blot. 

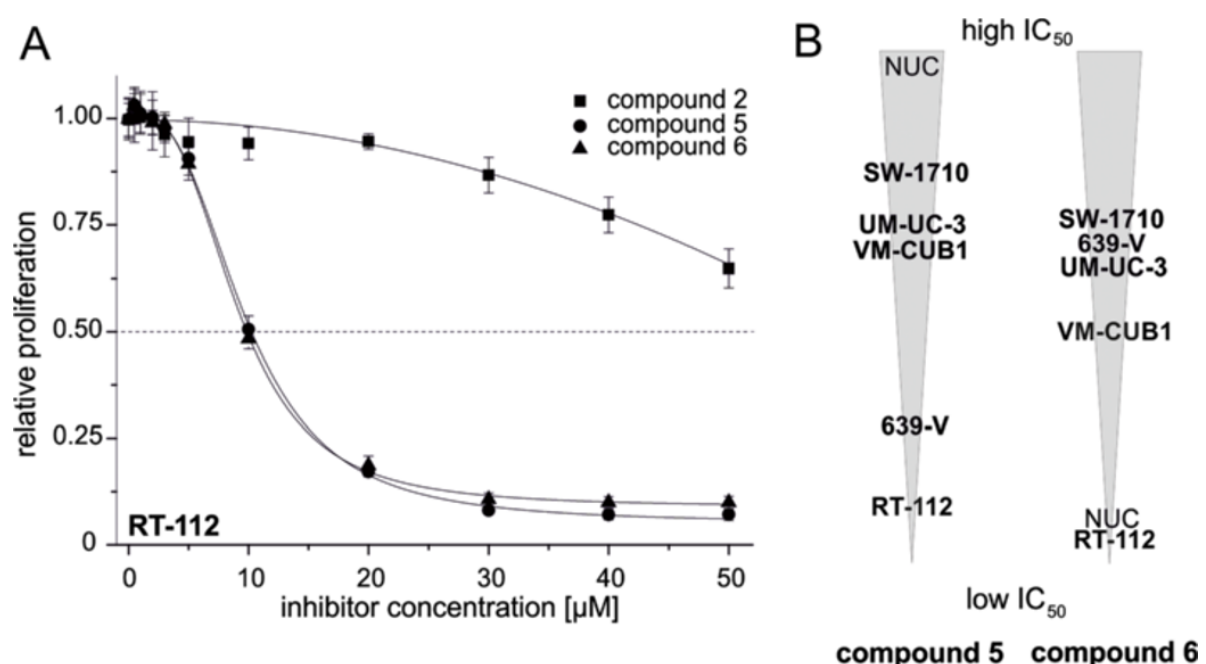

Figure 5 Dose-dependent effects of three different HDAC8 specific inhibitors on viability of urothelial cancer cell lines. (A) Several urothelial cancer cell lines were treated with different concentrations of HDAC8 inhibitors. Here, the dose-response curves of the UCC RT-112 are shown for compound 2, compound 5 and compound 6 after $72 \mathrm{~h}$ inhibitor treatment as measured by ATP-assay ( compound 2; $\bullet$ compound 5; $\boldsymbol{\Delta}$ compound 6). The calculated $I_{50}$ value in this cell line for compound 2 is greater than $50 \mu \mathrm{M}$, for compound 5 it is $9.7 \mu \mathrm{M}$ and for compound 6 it is $9.1 \mu \mathrm{M}$. (B) Sensitivity of urothelial cancer cell lines and one representative normal uroepithelial control to compound 5 and compound 6 after $72 \mathrm{~h}$ of treatment. The $\mathrm{IC}_{50}$ of compound 2 was only reached at concentrations near $50 \mu \mathrm{M}$. The cell lines outlined by bold letters were used for the functional experiments.

RT-112 and VM-CUB1 cells an increase of p21 protein level could be observed. Expression decreased in the cell lines SW-1710, 639-V and UM-UC-3 after c6 treatment and in the two former cell lines also after c5 treatment (Figure 8). An increase of acetylated $\alpha$-tubulin was detected in all cell lines after c5 and c6 inhibitor treatment (Figure 8).
Effects of HDAC8 targeting on cell cycle and apoptosis in urothelial cancer cell lines

To further characterize the impact of HDAC8 on cell cycle distribution UCCs were analyzed by flow cytometry after either knockdown or inhibitor treatment (Figure 9). Knockdown of HDAC8 resulted in a significant shift in cell cycle distribution only in SW-1710 cells, showing

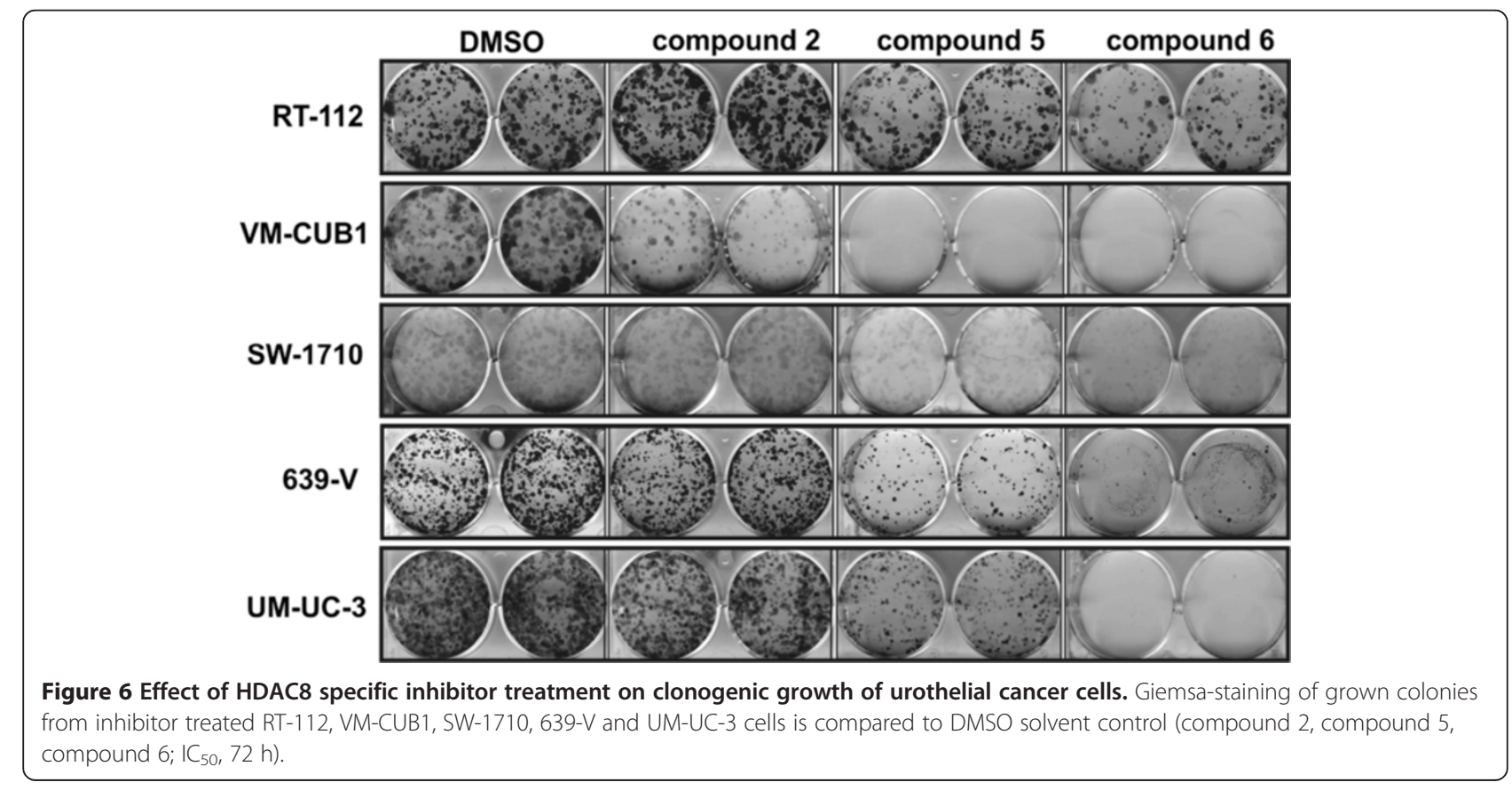




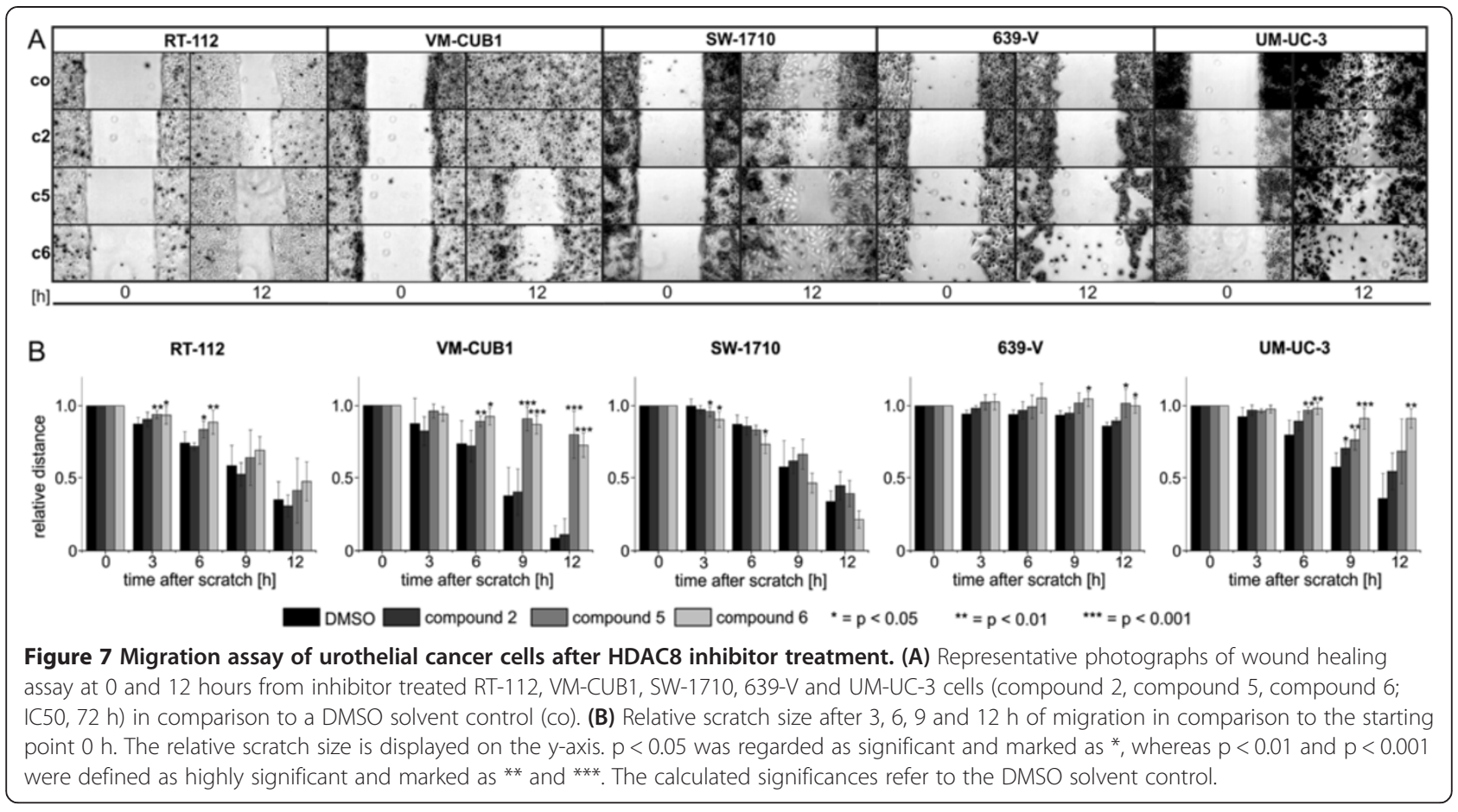

an S-phase-decrease. In the other UCCs no significant changes were observed (Figure 9A). In contrast, pharmacological inhibition of HDAC 8 by $\mathrm{c} 5$ and $\mathrm{c} 6$ resulted in a significant increase of the sub-G1 fraction in the UCCs VM-CUB1 and SW-1710 and a significant decrease of the G1-fraction in VM-CUB1, SW-1710, 639-V and UM-UC-3 cells (Figure 9B). Further, indications of a $\mathrm{G} 2 / \mathrm{M}$-arrest were observed after c5 and c6 treatment in VM-CUB1, SW-1710, 639-V and UM-UC-3 cells.

\section{HDAC activity and compensation mechanism during} HDAC8 treatment

Following HDAC8 knockdown or pharmacological inhibition, no effects on the acetylation status of histone H3 were observed (Figure 10). In contrast, acetylation of $\mathrm{H} 4$ increased after inhibitor treatment in RT-112 (Figure 10B). In addition, a slight increase of $\mathrm{H} 4$ acetylation was observed after c5 and c6 treatment in the cell line 639-V (Figure 10B). No effects on the acetylation status of $\mathrm{H} 4$ were seen following HDAC8 knockdown (Figure 10A).

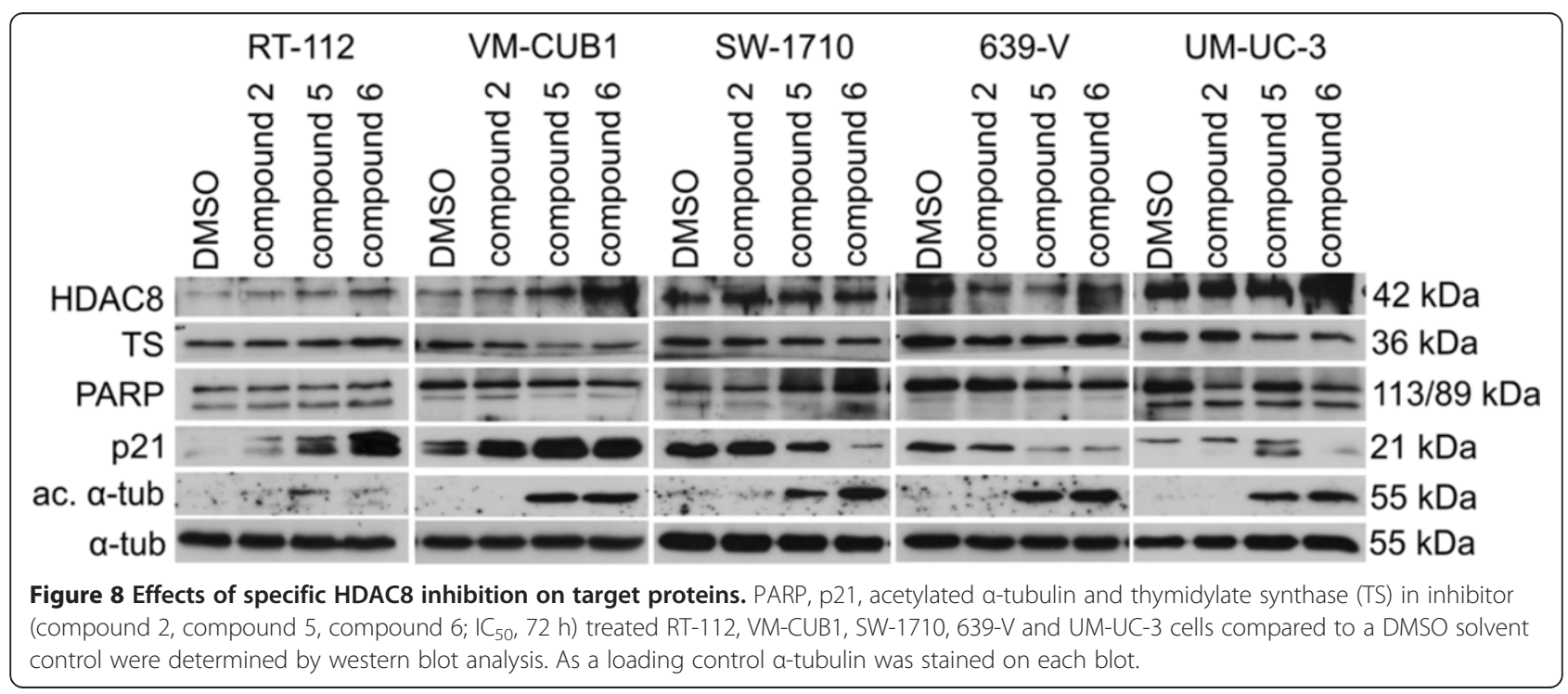




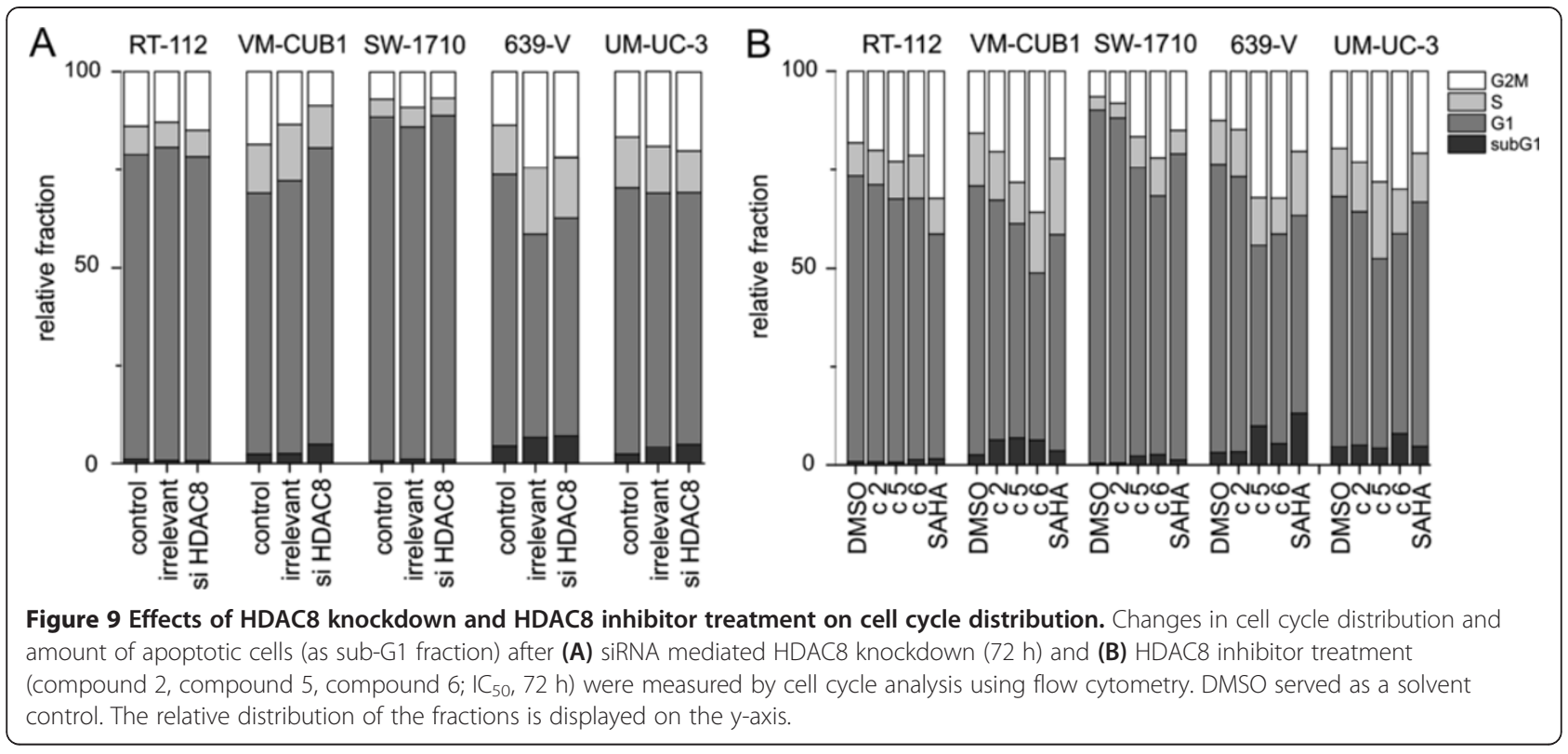

To investigate whether inhibition of HDAC8 might be counteracted by concomitant upregulation of other class I-HDACs (HDAC1, HDAC2 and HDAC3) their expression levels were compared by real-time PCR and western blot analysis (Figures 11 and 12). In brief, HDAC1, HDAC2 and HDAC3 mRNA levels exhibited variable changes after siRNA-mediated knockdown of HDAC8. Both significant up-and downregulation of specific HDACs were observed. In particular, either HDAC1 or HDAC2 seems to become upregulated after HDAC8 knockdown (Figure 11A). Western blot analysis shown in Figure 11B revealed a decrease of HDAC2 protein in RT-112 cells

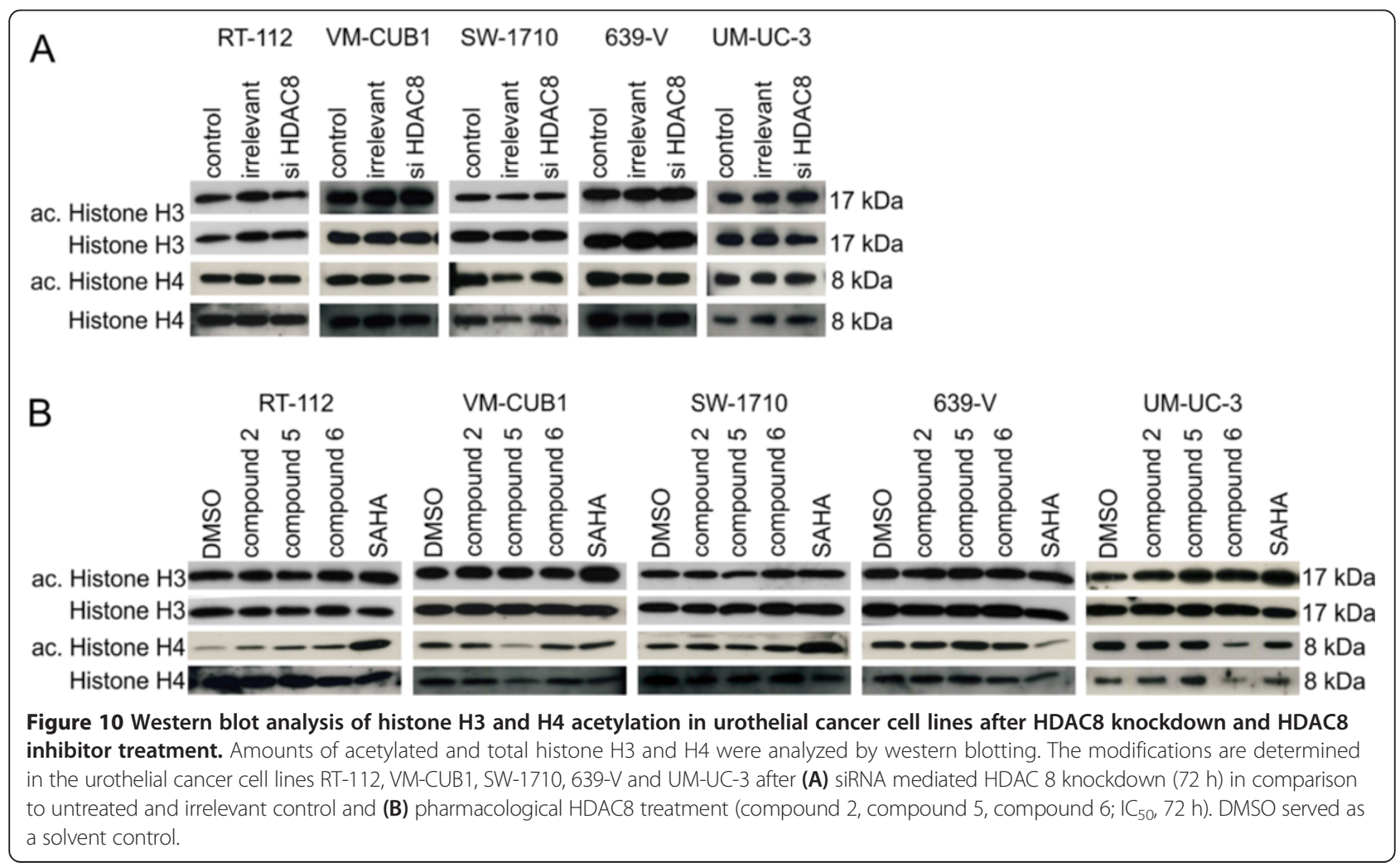



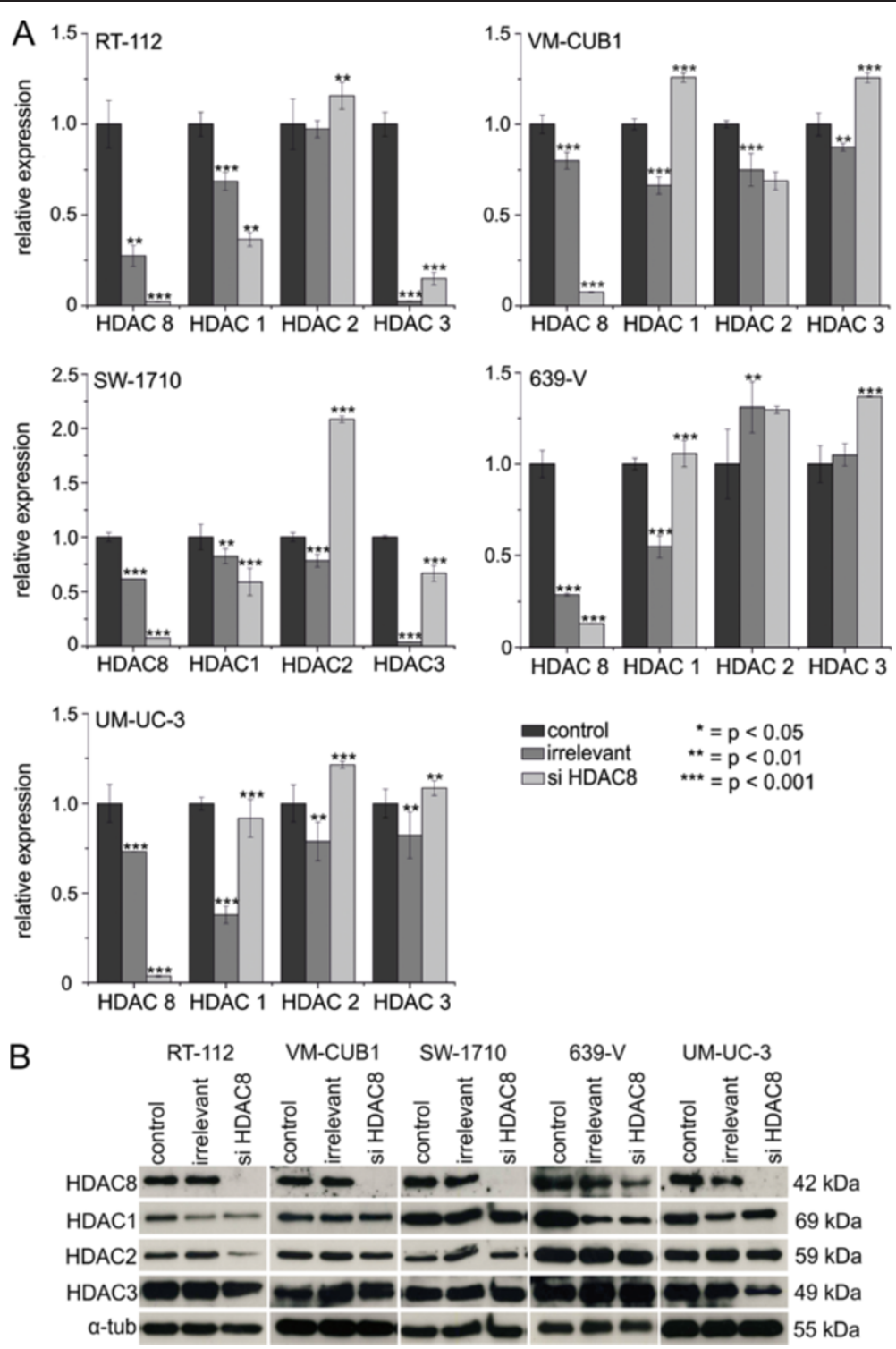

Figure 11 Compensation mechanism after HDAC8 knockdown in RT-112, VM-CUB1, SW-1710, 639-V and UM-UC-3 cells. Effects of siRNA mediated HDAC8 knockdown on (A) mRNA and (B) protein expression levels of the class I histone deacetylase HDAC8, HDAC1, HDAC2 and HDAC3 (72 h) in comparison to untreated and irrelevant control. The mRNA expression values were measured by quantitative RT-PCR analysis and were normalized to TBP as a reference gene. $p<0.05$ was regarded as significant and marked as *, whereas $p<0.01$ and $p<0.001$ were defined as highly significant and marked as ${ }^{* *}$ and ${ }^{* * *}$. Protein expression levels were analyzed by western blotting, and a-tubulin was stained on each blot as a loading control.

and HDAC3 protein in UM-UC-3 cells after siRNA mediated HDAC8 knockdown. No significant deregulation of other class I-HDACs took place (Figure 11B).

Measurements of mRNA expression after pharmacological inhibition of HDAC8 showed significant, but overall slight decreases or increases of the expression of several HDACs in the UCC (Figure 12A). Apart from a slightly reduced expression of HDAC1 and HDAC2/3 in SW-1710 and VM-CUB1 cells, no changes of protein expression were observed after c5 and c6 treatment (Figure 12B).

\section{Discussion}

In this study we present the first systematic analysis of HDAC8 expression and function in urothelial cancer using a set of bladder cancer cell lines representative for the heterogeneity of this tumor. The aim of our study was to evaluate the potential of HDAC8 as a therapeutic target.

Overexpression of HDAC8 has been reported in a considerable number of different cancer entities [26,34,36,37]. In neuroblastoma, in particular, HDAC8 expression was significantly correlated with further poor prognostic 

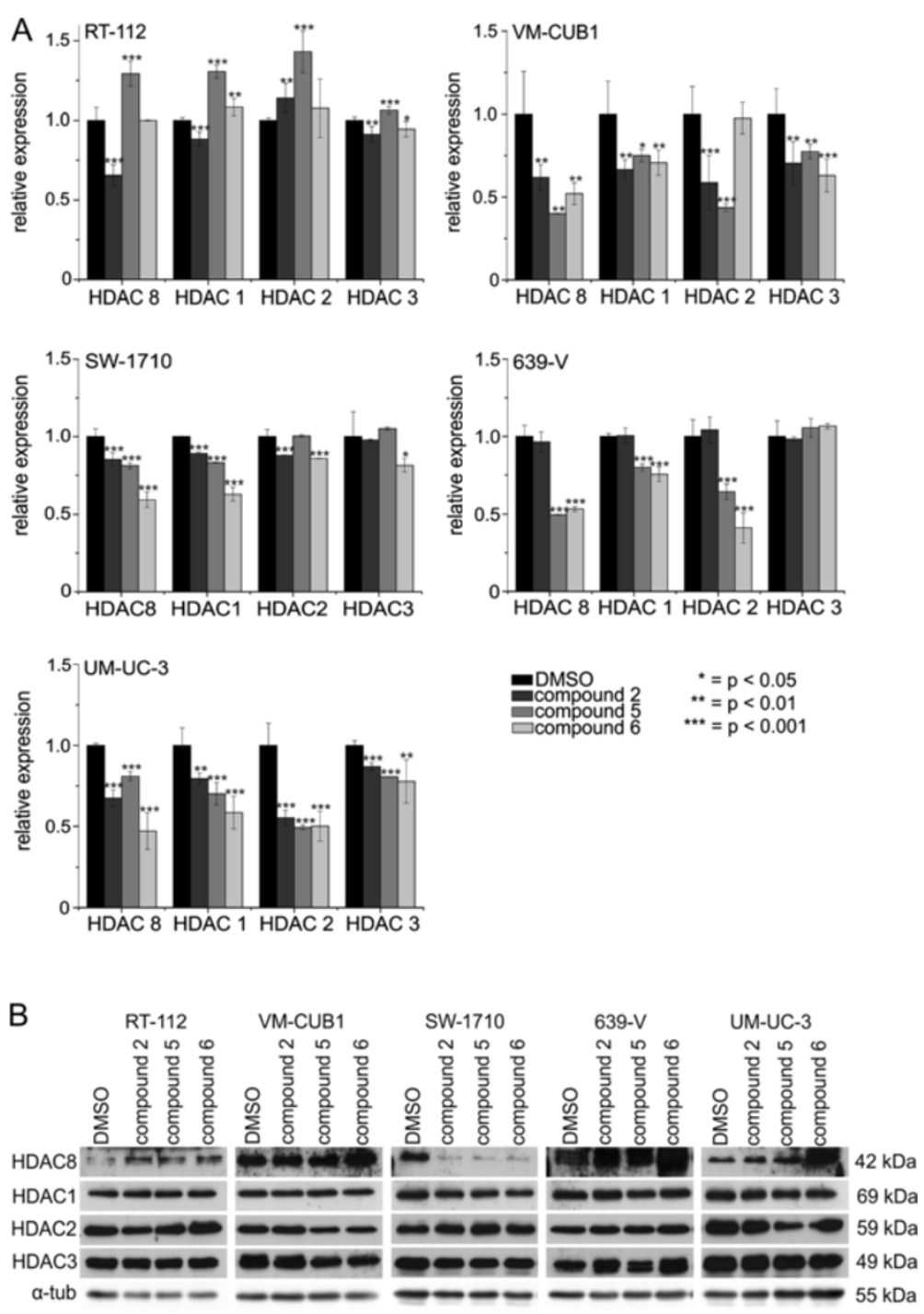

Figure 12 Compensation mechanism after specific HDAC8 inhibition in RT-112, VM-CUB1, SW-1710, 639-V and UM-UC-3 cells. Effects of HDAC8 inhibitor treatment on (A) mRNA and (B) protein expression of the class I histone deacetylases HDAC8, HDAC1, HDAC2 and HDAC3, compared to DMSO solvent control (compound 2, compound 5, compound 6; I $C_{50}, 72 \mathrm{~h}$ ). The mRNA expression values were measured by quantitative RT-PCR analysis and were normalized to TBP as a reference gene. $p<0.05$ was regarded as significant and marked as *, whereas $p<0.01$ and $p<0.001$ were defined as highly significant and marked as ** and ${ }^{* * *}$. The calculated significances of the treated value refer to the DMSO solvent control. Protein expression levels were analyzed by western blotting, and a-tubulin was stained on each blot as a loading control.

markers as well as poor overall and progression-free survival. SiRNA-mediated knockdown and pharmacological inhibition of HDAC8 in neuroblastoma significantly decreased proliferation rate and reduced clonogenic growth, cell cycle arrest, and differentiation [34]. In hepatocellular carcinoma HDAC8 knockdown also suppresses cell proliferation and enhances apoptosis via elevated expression of p53 and acetylation of p53 at Lys382 [36].

As there were indications from our own and other data that HDAC8 is often upregulated in urothelial carcinoma as well $[39,44]$, the question arose whether HDAC8 might be a potential target for anticancer treatment in this tumor.
In urothelial cancer cell lines, a variable expression of HDAC8 was observed both at mRNA and protein level [39]. Importantly, mRNA expression levels were comparable to neuroblastoma and breast cancer cells (data not shown). An according variability has also been reported from investigations in further malignomas, e.g. hepatocellular carcinoma cell lines, were also a broad range of HDAC8 expression was observed in cancer cell lines [36]. Differences between mRNA and protein expression indicate that HDAC8 expression and activity in UCCs may be regulated both transcriptionally and on the protein level, e.g. by protein kinase A (PKA) phosphorylation [30,31]. In addition, in our UCC panel, a low HDAC8 expression was 
predominantly observed in UCCs with an epithelial phenotype. Therefore, to cover this range both on protein and mRNA level, we chose to apply a panel of 6 cell lines representing the heterogeneity of the HDAC8 expression instead of focusing on one urothelial cancer cell line.

SiRNA targeting of HDAC8 in UCCs caused a significant reduction of proliferation up to $45 \%$ and inhibited clonogenic growth in a cell line-dependent manner. These results were comparable to observations in hepatocellular carcinoma (HCC) and neuroblastoma cells [34,36]. Clonogenic growth was most decreased in the mesenchymal cell line SW-1710 which presented the highest HDAC8 protein expression. Treatment with the three different HDAC8 inhibitors c2, c5 and c6 revealed a low sensitivity of UCCs for $\mathrm{c} 2$ with a calculated $\mathrm{IC}_{50}$ value greater than $50 \mu \mathrm{M}$. In contrast, neuroblastoma cell lines (BE (2)-C) were more sensitive to treatment with $\mathrm{c} 2$, presenting $\mathrm{IC}_{50}$ values in a range of 10 to $40 \mu \mathrm{M}$. In these cells, the HDAC8 inhibitor c2 yielded an similar phenotype at a concentration similar to the in vitro $\mathrm{IC}_{50}$ of $\mathrm{c} 2$ against HDAC8 [41]. None of the UCCs was inhibited substantially at this concentration by pharmacological treatment with $\mathrm{c} 2$.

The inhibitors c5 and c6 significantly reduced the viability of all UCCs, with half inhibitory concentrations between 9 and $20.8 \mu \mathrm{M}$. These differences follow the order of the affinity of the inhibitors for HDAC8 in vitro [41]. Though in vitro affinity of c5 and c6 is $20-50$ fold higher compared to $\mathrm{c} 2$, in vivo effects on UCC were not as strong as expected.

Focusing on morphological features of UCCs, the data suggested that cells with an epithelial phenotype and low HDAC8 expression are more sensitive towards pharmacological inhibition of HDAC8 with c5 and c6 compared to cells with a mesenchymal phenotype. Specifically, SW-1710 cells (mesenchymal, elevated HDAC8 expression) were least sensitive to the inhibitors c5 and c6 while RT112 cells (epithelial, lowest HDAC8 expression) responded to treatment with c5 and c6 already at low concentrations.

As recently shown in endometrial stroma sarcoma cells, HDAC inhibition may be counteracted by increased activity of the PI3K pathway in PTEN-deficient cells [45]. In our cell line panel, UM-UC-3 are PTEN-deficient, resulting in increased PI3K activity. However, this cell line was not exceptionally resistant either in our previous study using pan-HDAC inhibition [39] or in the present study with HDAC8-specific inhibitors. Accordingly, at least in urothelial cancer, PTEN deficiency does not seem to have a decisive impact on the efficacy of HDAC inhibitors.

Effects of siRNA mediated downregulation and pharmacological inhibition on urothelial cancer cell lines were not thoroughly consistent. Differences might be explained by several factors. For example, knockdown depletes the protein thereby not only affecting enzymatic but also other protein functions for example complex assembly.
Inhibitor treatment ideally only suppresses the enzymatic activity while further protein functions should not be affected. Accordingly, also compensatory mechanisms might be different in both conditions. Comparing expression levels of further class I HDACs after knockdown of HDAC8 as well as after pharmacological inhibition, only minor changes were observed. Although upregulation of HDAC1 or HDAC2 was a little more consistently observed after HDAC8 knockdown, they can hardly explain the difference between knockdown and inhibition by c 5 or c6. More likely, the stronger effects of the inhibitors may be due to inhibition of other targets in addition to HDAC8.

Neither HDAC8 knockdown nor pharmacological treatment with any compound (except the SAHA control) led to a change in histone $\mathrm{H} 3$ or $\mathrm{H} 4$ acetylation, a widely used surrogate marker for intracellular HDAC inhibition. This finding suggests that HDAC8, as expected, does not substantially affect overall histone acetylation. In addition, this does also indicate that inhibitor treatment seems to be iso-enzyme specific as other class I HDACs seemed to be not affected. This was also observed in neuroblastoma cell lines after treatment of HDAC8. Global Histone H4 acetylation was not affected by HDAC8 knockdown or by selective inhibitor treatment [34].

In contrast, HDAC8 knockdown in some cell lines and treatment with c5 or c6 resulted in a strong increase of acetylated $\alpha$-tubulin. The latter finding is in accord with previous findings in HeLa and HEK293 cells [45]. The cytoplasmic protein $\alpha$-tubulin is especially a substrate of HDAC6 which is predominantly localized in the cytoplasm [23]. HDAC6 influences the cytoskeleton and cell motility via deacetylation of $\alpha$-tubulin and other cytoskeleton proteins [46]. In vitro, c5 and c6 do not inhibit HDAC6 efficiently. Thus, the best explanation for these observations is that in vivo HDAC8 directly or indirectly influences $\alpha$-tubulin acetylation. Similar discrepancies between in vitro and in vivo activity of an isoenzyme-selective HDAC inhibitor on tubulin acetylation have been observed by others for valproic acid [47]. These effects on $\alpha$-tubulin acetylation may relate to the inhibition of cell migration by c5 and c6 we observed in UC cell lines. However, inhibition of HDAC6 as such does not inhibit migration of UCC as efficiently as the HDAC8 inhibitors c5 and c6 [48].

The effects of siRNA mediated knockdown of HDAC8 on cell cycle and apoptosis were limited and few significant effects were seen, such as a decreased S-phase fraction in VM-CUB1 and small changes in thymidylate synthase and $\mathrm{p} 21$ expression. In the neuroblastoma cell line BE (2)-C, a G0/G1 arrest has been detected after siRNA-mediated knockdown of HDAC8. This G0/G1 arrest induced by HDAC8 knockdown was associated with p21 mRNA upregulation [34]. In contrast, no effect on the cell cycle was observed in the hepatocellular carcinoma cell 
lines BEL-7402 and Hep-G2 [36]. This observation fits with our own marginal effects after siRNA-mediated HDAC8 knockdown. The level of apoptosis induction in BEL-7402 and Hep-G2 cells after siRNA-mediated targeting of HDAC8 were comparable to the increase of the subG1fraction in individual urothelial carcinoma cell lines after targeting of HDAC8 [36].

Concerning the use of inhibitors, effects of pharmacological inhibition on cell cycle distribution by $\mathrm{c} 2$ were, as expected, only minor. In contrast, pharmacological inhibition by c5 or c6 resulted in a significant albeit low increase of the sub-G1 fraction in two out of five cell lines and in an apparent $\mathrm{G} 2 / \mathrm{M}$-arrest in four out of five cell lines. Consequently, p21 increased in two cell lines and thymidylate synthase decreased in all but one.

\section{Conclusions}

HDAC8 is deregulated in UCCs resulting in variable mRNA and protein expression levels. Suppression and pharmacological inhibition of HDAC8 had significant, but overall minor impacts on cell proliferation, clonogenic growth and migration. These effects were comparable to findings in other cancer entities. Furthermore, pharmacological inhibition of HDAC8 induced a G2/ $\mathrm{M}$-arrest. However, those effects were observed only at drug concentrations probably not appropriate for the use in patients. Neither HDAC8 mRNA nor protein expression levels were reliable predictive marker for sensitivity to HDAC8 inhibition.

In summary, HDAC8 on its own does not seem to constitute a promising drug target in bladder cancer. Whether selective HDAC8 inhibition may synergize with either conventional chemotherapeutics or further targeted antitumoral compounds remains to be further explored. Interestingly, in this respect, the compounds c5 and c6 which are efficient inhibitors of HDAC8 may have additional cellular targets which need to be further elucidated.

\section{Competing interests}

The authors declare that they have no competing interests.

\section{Authors' contributions}

$\mathrm{ML}, \mathrm{MJH}, \mathrm{AK}$, WAS and GN conceived and designed the study. ML and MJH carried out the performed experiments. ML, WAS and GN carried out data analysis and prepared the initial manuscript. SMU provided crucial reagents. $\mathrm{MJH}, \mathrm{AK}, \mathrm{SMU}$, WAS and GN contributed to the manuscript. WAS and GN supervised the project. All authors read and approved the final manuscript.

\section{Acknowledgements}

The work was supported by a grant from the Deutsche Forschungsgemeinschaft to GN (NI 1398/1-1). AK and WAS were supported by the Krebsgesellschaft NRW. The authors thank Christiane Hader for her excellent technical assistance.

\section{Author details}

'Department of Urology, Heinrich-Heine-University, Medical Faculty, Moorenstr. 5, Duesseldorf 40225, Germany. ${ }^{2}$ Department of Chemistry, Ithaca College, Ithaca, NY 14850, USA.
Received: 29 April 2014 Accepted: 27 June 2014

Published: 10 July 2014

\section{References}

1. Ferlay J, Shin HR, Bray F, Forman D, Mathers C, Parkin DM: Estimates of worldwide burden of cancer in 2008: GLOBOCAN 2008. Int J Cancer 2010, 127:2893-2917.

2. Witjes JA, Comperat E, Cowan NC, De Santis M, Gakis G, Lebret T, Ribal MJ, Van der Heijden AG, Sherif A: EAU Guidelines on Muscle-invasive and Metastatic Bladder Cancer: Summary of the 2013 Guidelines. Eur Urol 2014, 65(4):778-92.

3. Goebell PJ, Vom Dorp F, Rodel C, Frohneberg D, Thuroff JW, Jocham D, Stief C, Roth S, Knuchel R, Schmidt KW, Kausch I, Zaak D, Wiesner C, Miller K, Sauer R, Rübben H: Noninvasive and invasive bladder cancer: diagnostics and treatment. Der Urologe Ausg A 2006, 45:873-884.

4. Roberts JT, von der Maase H, Sengelov L, Conte PF, Dogliotti L, Oliver T, Moore MJ, Zimmermann A, Arning M: Long-term survival results of a randomized trial comparing gemcitabine/cisplatin and methotrexate/ vinblastine/doxorubicin/cisplatin in patients with locally advanced and metastatic bladder cancer. Ann Oncol 2006, 17(Suppl 5):v118-122.

5. Sternberg CN, Bellmunt J, Sonpavde G, Siefker-Radtke AO, Stadler WM, Bajorin DF, Dreicer R, George DJ, Milowsky MI, Theodorescu D, Vaughn DJ, Galsky MD, Soloway MS, Quinn DI, International Consultation on Urologic Disease-European Association of Urology Consultation on Bladder Cancer 2012: ICUD-EAU International Consultation on Bladder Cancer 2012: Chemotherapy for urothelial carcinoma-neoadjuvant and adjuvant settings. Eur Urol 2013, 63:58-66.

6. Butler JS, Koutelou E, Schibler AC, Dent SY: Histone-modifying enzymes: regulators of developmental decisions and drivers of human disease. Epigenomics 2012, 4:163-177.

7. Dawson MA, Kouzarides T: Cancer epigenetics: from mechanism to therapy. Cell 2012, 150:12-27.

8. Gui Y, Guo G, Huang Y, Hu X, Tang A, Gao S, Wu R, Chen C, Li X, Zhou L, He $M$, Li Z, Sun X, Jia W, Chen J, Yang S, Zhou F, Zhao X, Wan S, Ye R, Liang C, Liu Z, Huang P, Liu C, Jiang H, Wang Y, Zheng H, Sun L, Liu X, Jiang Z, et al: Frequent mutations of chromatin remodeling genes in transitional cell carcinoma of the bladder. Nat Genet 2011, 43:875-878.

9. Ahmad M, Hamid A, Hussain A, Majeed R, Qurishi Y, Bhat JA, Najar RA, Qazi AK, Zargar MA, Singh SK, Saxena AK: Understanding histone deacetylases in the cancer development and treatment: an epigenetic perspective of cancer chemotherapy. DNA Cell Biol 2012, 31(Suppl 1):S62-71.

10. Marks P, Rifkind RA, Richon VM, Breslow R, Miller T, Kelly WK: Histone deacetylases and cancer: causes and therapies. Nat Rev Canc 2001, 1:194-202.

11. de Ruijter AJ, van Gennip AH, Caron HN, Kemp S, van Kuilenburg AB: Histone deacetylases (HDACs): characterization of the classical HDAC family. Biochem J 2003, 370:737-749.

12. Gregoretti IV, Lee YM, Goodson HV: Molecular evolution of the histone deacetylase family: functional implications of phylogenetic analysis. J Mol Biol 2004, 338:17-31.

13. Witt O, Deubzer HE, Milde T, Oehme I: HDAC family: What are the cancer relevant targets? Cancer Lett 2009, 277:8-21.

14. Weichert W, Roske A, Gekeler V, Beckers T, Ebert MP, Pross M, Dietel M, Denkert C, Rocken C: Association of patterns of class I histone deacetylase expression with patient prognosis in gastric cancer: a retrospective analysis. Lancet Oncol 2008, 9:139-148.

15. Weichert W, Roske A, Gekeler V, Beckers T, Stephan C, Jung K, Fritzsche FR, Niesporek S, Denkert C, Dietel M, Kristiansen G: Histone deacetylases 1, 2 and 3 are highly expressed in prostate cancer and HDAC2 expression is associated with shorter PSA relapse time after radical prostatectomy. Br J Cancer 2008, 98:604-610

16. Weichert W, Denkert C, Noske A, Darb-Esfahani S, Dietel M, Kalloger SE, Huntsman DG, Kobel M: Expression of class I histone deacetylases indicates poor prognosis in endometrioid subtypes of ovarian and endometrial carcinomas. Neoplasia 2008, 10:1021-1027.

17. Yang XJ, Seto E: The Rpd3/Hda1 family of lysine deacetylases: from bacteria and yeast to mice and men. Nat Rev Mol Cell Biol 2008, 9:206-218.

18. Grunstein M: Histone acetylation in chromatin structure and transcription. Nature 1997, 389:349-352.

19. Choudhary C, Kumar C, Gnad F, Nielsen ML, Rehman M, Walther TC, Olsen JV, Mann M: Lysine acetylation targets protein complexes and co-regulates major cellular functions. Science 2009, 325:834-840. 
20. Patel J, Pathak RR, Mujtaba S: The biology of lysine acetylation integrates transcriptional programming and metabolism. Nutr Metabol 2011, 8:12.

21. Gu W, Roeder RG: Activation of p53 sequence-specific DNA binding by acetylation of the p53 C-terminal domain. Cell 1997, 90:595-606.

22. Rolef Ben-Shahar T, Heeger S, Lehane C, East P, Flynn H, Skehel M, Uhlmann F: Eco1-dependent cohesin acetylation during establishment of sister chromatid cohesion. Science 2008, 321:563-566.

23. Li Y, Shin D, Kwon SH: Histone deacetylase 6 plays a role as a distinct regulator of diverse cellular processes. FEBS J 2013, 280:775-793.

24. Valente S, Mai A: Small-molecule inhibitors of histone deacetylase for the treatment of cancer and non-cancer diseases: a patent review (2011 - 2013). Expert Opin Ther Pat 2014, 24(4):401-15.

25. Ververis K, Hiong A, Karagiannis TC, Licciardi PV: Histone deacetylase inhibitors (HDACls): multitargeted anticancer agents. Biologics 2013, 7:47-60.

26. Nakagawa M, Oda Y, Eguchi T, Aishima S, Yao T, Hosoi F, Basaki Y, Ono M, Kuwano M, Tanaka M, Tsuneyoshi M: Expression profile of class I histone deacetylases in human cancer tissues. Oncol Rep 2007, 18:769-774.

27. Hu E, Chen Z, Fredrickson T, Zhu Y, Kirkpatrick R, Zhang GF, Johanson K, Sung CM, Liu R, Winkler J: Cloning and characterization of a novel human class I histone deacetylase that functions as a transcription repressor. J Biol Chem 2000, 275:15254-15264.

28. Van den Wyngaert I, de Vries W, Kremer A, Neefs J, Verhasselt P, Luyten WH, Kass SU: Cloning and characterization of human histone deacetylase 8. FEBS Lett 2000, 478:77-83.

29. Buggy JJ, Sideris ML, Mak P, Lorimer DD, Mclntosh B, Clark JM: Cloning and characterization of a novel human histone deacetylase, HDAC8. Biochem J 2000, 350(Pt 1):199-205.

30. Lee $H$, Rezai-Zadeh $N$, Seto E: Negative regulation of histone deacetylase 8 activity by cyclic AMP-dependent protein kinase A. Mol Cell Biol 2004, 24:765-773

31. Vannini A, Volpari C, Filocamo G, Casavola EC, Brunetti M, Renzoni D, Chakravarty P, Paolini C, De Francesco R, Gallinari P, Steinkühler C, Di Marco $S:$ Crystal structure of a eukaryotic zinc-dependent histone deacetylase, human HDAC8, complexed with a hydroxamic acid inhibitor. Proc Natl Acad Sci U S A 2004, 101:15064-15069.

32. Waltregny D, North B, Van Mellaert F, de Leval J, Verdin E, Castronovo V: Screening of histone deacetylases (HDAC) expression in human prostate cancer reveals distinct class I HDAC profiles between epithelial and stromal cells. Eur J Histochem 2004, 48:273-290.

33. Waltregny D, De Leval L, Glenisson W, Ly Tran S, North BJ, Bellahcene A, Weidle U, Verdin E, Castronovo V: Expression of histone deacetylase 8, a class I histone deacetylase, is restricted to cells showing smooth muscle differentiation in normal human tissues. Am J Pathol 2004, 165:553-564.

34. Oehme I, Deubzer HE, Wegener D, Pickert D, Linke JP, Hero B, KoppSchneider A, Westermann F, Ulrich SM, von Deimling A, Fischer M, Witt O: Histone deacetylase 8 in neuroblastoma tumorigenesis. Clin Cancer Res 2009, 15:91-99.

35. Balasubramanian S, Ramos J, Luo W, Sirisawad M, Verner E, Buggy JJ: A novel histone deacetylase 8 (HDAC8)-specific inhibitor PCl-34051 induces apoptosis in T-cell lymphomas. Leukemia 2008, 22:1026-1034.

36. Wu J, Du C, Lv Z, Ding C, Cheng J, Xie H, Zhou L, Zheng S: The up-regulation of histone deacetylase 8 promotes proliferation and inhibits apoptosis in hepatocellular carcinoma. Dig Dis Sci 2013, 58:3545-3553.

37. Park SY, Jun JA, Jeong KJ, Heo HJ, Sohn JS, Lee HY, Park CG, Kang J: Histone deacetylases 1, 6 and 8 are critical for invasion in breast cancer. Oncol Rep 2011, 25:1677-1681.

38. Lee H, Sengupta N, Villagra A, Rezai-Zadeh N, Seto E: Histone deacetylase 8 safeguards the human ever-shorter telomeres 1B (hEST1B) protein from ubiquitin-mediated degradation. Mol Cell Biol 2006, 26:5259-5269.

39. Niegisch G, Knievel J, Koch A, Hader C, Fischer U, Albers P, Schulz WA: Changes in histone deacetylase (HDAC) expression patterns and activity of HDAC inhibitors in urothelial cancers. Urol Oncol 2013, 31:1770-1779.

40. Swiatkowski S, Seifert HH, Steinhoff C, Prior A, Thievessen I, Schliess F, Schulz WA: Activities of MAP-kinase pathways in normal uroepithelial cells and urothelial carcinoma cell lines. Exp Cell Res 2003, 282:48-57.

41. Krennhrubec K, Marshall BL, Hedglin M, Verdin E, Ulrich SM: Design and evaluation of 'Linkerless' hydroxamic acids as selective HDAC8 inhibitors. Bioorg Med Chem Lett 2007, 17:2874-2878.

42. Nicoletti I, Migliorati G, Pagliacci MC, Grignani F, Riccardi C: A rapid and simple method for measuring thymocyte apoptosis by propidium iodide staining and flow cytometry. J Immunol Meth 1991, 139:271-279.
43. Shechter D, Dormann HL, Allis CD, Hake SB: Extraction, purification and analysis of histones. Nat Protocol 2007, 2:1445-1457.

44. Lee JS, Leem SH, Lee SY, Kim SC, Park ES, Kim SB, Kim SK, Kim YJ, Kim WJ, Chu IS: Expression signature of E2F1 and its associated genes predict superficial to invasive progression of bladder tumors. J Clin Oncol 2010, 28:2660-2667.

45. Quan P, Moinfar F, Kufferath I, Absenger M, Kueznik T, Denk H, Zatloukal K, Haybaeck J: Effects of Targeting Endometrial Stromal Sarcoma Cells via Histone Deacetylase and PI3K/AKT/mTOR Signaling. Anticancer Res 2014, 34:2883-2897.

46. Boyault C, Sadoul K, Pabion M, Khochbin S: HDAC6, at the crossroads between cytoskeleton and cell signaling by acetylation and ubiquitination. Oncogene 2007, 26:5468-5476.

47. Yagi Y, Fushida S, Harada S, Kinoshita J, Makino I, Oyama K, Tajima H, Fujita H, Takamura H, Ninomiya I, Fujimura T, Ohta T, Yashiro M, Hirakawa K: Effects of valproic acid on the cell cycle and apoptosis through acetylation of histone and tubulin in a scirrhous gastric cancer cell line. J Exp Clin Cancer Res 2010, 29:149.

48. Rosik L, Niegisch G, Fischer U, Jung M, Schulz WA, Hoffmann MJ: Limited efficacy of specific HDAC6 inhibition in urothelial cancer cells. Canc Biol Ther 2014, 15:742-57.

\section{doi:10.1186/s13046-014-0059-8}

Cite this article as: Lehmann et al.: Histone deacetylase 8 is deregulated in urothelial cancer but not a target for efficient treatment. Journal of Experimental \& Clinical Cancer Research 2014 33:59.

\section{Submit your next manuscript to BioMed Central and take full advantage of:}

- Convenient online submission

- Thorough peer review

- No space constraints or color figure charges

- Immediate publication on acceptance

- Inclusion in PubMed, CAS, Scopus and Google Scholar

- Research which is freely available for redistribution
C Biomed Central 